\title{
The Effect of Dispersoids and Processing Variables on Grain Refinement of Aluminium Alloys Deformed by ECAE
}

\author{
M. Berta ${ }^{a}$ and P. B. Prangnell \\ Manchester Materials Science Centre, The University of Manchester, Grosvenor Street, \\ Manchester, M1 7HS, UK.
}

e-mail: ${ }^{a}$ m.berta@postgrad.umist.ac.uk, ${ }^{\mathrm{b}}$ philip.prangnell@manchester.ac.uk

Keywords: ECAE, severe deformation, grain refinement, dispersoids, processing route, Al-Sc alloys.

\begin{abstract}
The effect of fine, non-shearable, dispersoids on the grain refinement of aluminium alloys, severely deformed by ECAE, has been studied using a model Al-0.2\% Sc alloy, during deformation by Routes $\mathrm{A}$ and $\mathrm{B}_{\mathrm{C}}$ (+90degrees rotation) using a $120^{\circ}$, or $90^{\circ}$, die. The microstructure in the dispersoid-containing alloy was compared to a single-phase alloy using high resolution EBSD analysis. With Route A the presence of fine dispersoids was found to significantly retard the development of new high-angle grain boundaries and the formation of a fine grain structure, by homogenising slip and inhibiting microshear bands. This difference was greatly enhanced, using Route $\mathrm{B}_{\mathrm{C}}$. Similar results were obtained with the two die angles, but with Route A refinement tended to be slightly less effective when using the $90^{\circ}$ die.
\end{abstract}

\section{Introduction}

There has been considerable interest over the last decade in developing procedures for the production of metallic alloys with ultrafine grain (UFG) sizes [1]. In particular, the equal channel angular extrusion (ECAE) process has been the subject of many investigations and has been widely shown to be capable of producing sub-micron grained materials at ultra-high plastic strains [1-4]. Although much research has been conducted on the evolution of the deformation structure of UFG alloys produced by ECAE during severe deformation (e.g. [2,4]) there are still some fundamental issues that are poorly understood. In terms of the process, it is still not clear how the deformation Route and ECAE die angle, which controls the strain per cycle, influence the rate of refinement and final microstructure. For example, rotation of the billet between each extrusion cycle by $90^{\circ}$ using Route $\mathrm{B}_{\mathrm{C}}$ can increase, or reduce, the level of grain refinement compared to Route A (no rotation), depending on the die angle, die corner profile, and material [2,5-7]. The use of different die designs by various research groups has probably contributed to this lack of clarity.

Knowledge of the influence of basic material variables on the grain refinement process is also still incomplete. In particular, it is important to understand the effect of fine dispersoid particles, which are widely used to inhibit grain growth in superplastic UFG materials. Al-Sc alloys are an ideal model system for this purpose as they can be heat treated to develop very high densities of $\mathrm{Al}_{3} \mathrm{Sc}$ non-shearble fine dispersoid particles [8]. Previous work using Route A, with a $120^{\circ}$ die, has demonstrated that scandium dispersoids can lead to a lower rate of refinement compared to that seen in a single-phase material [8].

In this paper, the effect of $\mathrm{Al}_{3} \mathrm{Sc}$ dispersiods on the deformation microstructure after ECAE processing is further investigated by comparing their influence on the two most common processing Routes, $\mathrm{A}$ and $\mathrm{B}_{\mathrm{C}}$, when using two different die angles of $2 \phi=120$ and $90^{\circ}$. 


\section{Experimental}

A high purity Al- $0.2 \% \mathrm{Sc}$ model dispersoid forming alloy, and high purity single-phase Al$0.13 \% \mathrm{Mg}$ control material, were processed to obtain similar recrystallised starting grain structures with a $\sim 500 \mu \mathrm{m}$ grain size. The Al-0.2Sc alloy was further heat treated to develop a uniform distribution of fine coherent $\sim 20 \mathrm{~nm}$ diameter $\mathrm{Al}_{3} \mathrm{Sc}$ dispersoids, with an inter-particle spacing of the order of $100 \mathrm{~nm}$ (see [8] for full heat treatment details). Both alloys were deformed by ECAE at room temperature to a total von Mises effective strain of $\varepsilon_{\mathrm{vm}} \sim 10$, using Route $\mathrm{A}$ or Route $\mathrm{B}_{\mathrm{C}}$, with either a $90^{\circ}$ or $120^{\circ}$ die. The strain was calculated using Segal's original relationship for ideal simple shear; $\varepsilon_{\mathrm{vm}}=(2 / \sqrt{3}) \cot (\phi)$, where $2 \phi$ is the die angle [9]. The extrusion billets were $15 \mathrm{~mm}$ in diameter by $100 \mathrm{~mm}$ long and the two dies used had a sharp internal corner with no 'relief radius'. To obtain approximately the same strain with each die nine extrusion cycles were performed with the $90^{\circ}$ die and 15 with the $120^{\circ}$ die (the shear strain per cycle was $\gamma \sim 2$ and 1.15 for the $90^{\circ}$ and $120^{\circ}$ dies respectively).

The material's deformation structures were characterized using samples taken from the centre of the of the ECAE billet in the ND-ED plane, by high-resolution EBSD using a FEGSEM fitted with an HKL technology EBSD system. The spatial and angular resolutions of the systems were $>50 \mathrm{~nm}$ and $\sim 1^{\circ}$, respectively. A low misorientation cut-off of $1.5^{\circ}$ was used to minimise misorientation noise. Low angle boundaries (LAGBs) have been defined as having between $1.5^{\circ}$ and $15^{\circ}$ misorientations and high angle grain boundaries (HAGBs) greater than $15^{\circ}$ misorientation (depicted as black and light grey lines). Statistical analysis of the percentage HAGB area, mean boundary misorientations, and grain sizes have been taken from EBSD measurements of 20005000 grains (table 1 and 2). The grain sizes have been measured using the mean linear intercept method parallel and perpendicular to the main direction of alignment of the microstructure and from the equivalent circular diameter (ECD) after grain reconstruction from the EBSD data. The ECD data has was also used to determine the width of the grain size distributions from the standard deviation normalised with respect to the distribution average.

\section{Results and Discussion}

Severe deformation by Route A. The microstructures of the $\mathrm{Al}-0.13 \% \mathrm{Mg}$ and $\mathrm{Al}-0.2 \% \mathrm{Sc}$ processed by Route A to a strain of $\varepsilon_{\mathrm{vm}} \sim 10$, using the 90 and $120^{\circ}$ dies, are shown in example areas taken from larger EBSD maps in Fig. 1. Statistical data obtained from the full EBSD maps showing the fraction of HAGB area, mean boundary misorientations, and grain sizes are shown in table 1. It should be noted that the grain length linear intercept $\left(\lambda_{y}\right)$ can be unreliable with aligned SMG microstructures because the retained longer fibrous grains are frequently bent and do not align perfectly with the reference frame. After this ultra-high strain deformation, with a constant billet orientation, all the samples have a very refined fibrous grain structure with a high fraction of HAGB area (Figure $1 \mathrm{a}-\mathrm{b}$ ). The fibrous grains are aligned close to the billets extrusion direction. Although the grain structures appear reasonably similar, there are significant differences between the two materials and billets processed with the two die angles.

It can be seen from Fig. 1 that none of the billets are truly uniformly submicron grained, based on a HAGB being defined as having a $15^{\circ}$ misorientation, and contain significant proportion of subgrains and retained less large fibrous grain fragments. Of the four conditions, the sample with the most refined structure is the single-phase Al- $0.13 \mathrm{Mg}$ control alloy deformed in the $120^{\circ}$ die (Fig. 1a), which can be seen from Table 1 to also have the highest fraction of HAGB area (74\%), the lowest grain size and aspect ratio. When this material was deformed by the $90^{\circ}$ die, theoretically to the same effective strain, its microstructure was significantly less refined and contained more long 
ribbon grains typically seen at a lower strain in previous results using the $120^{\circ}$ die $\left(\varepsilon_{\mathrm{vm}} \sim 8\right)$ [10], this difference is also reflected in the statistical data in Table 1. A similar difference can be seen between the two Al-0.2Sc billets processed by the 120 and $90^{\circ}$ dies.

\begin{tabular}{|c|c|c|c|c|c|c|c|c|}
\hline \multirow{2}{*}{\multicolumn{2}{|c|}{ Route A }} & \multicolumn{5}{|c|}{ Mean Grain Size $(\mu \mathrm{m})$} & \multirow[b]{2}{*}{$\%$ HAGB } & \multirow[b]{2}{*}{ Misornt } \\
\hline & & $\lambda_{\mathrm{x}}$ & $\lambda_{\mathrm{y}}$ & $\lambda_{y} / \lambda_{x}$ & ECD & $\sigma_{\mathrm{SD}} / \mathrm{d}_{\mathrm{m}}$ & & \\
\hline Die: & Material & & & & & & & \\
\hline $120^{\circ}:$ & $\mathrm{Al}-0.13 \mathrm{Mg}$ & 0.48 & 0.85 & 1.8 & 0.87 & 0.72 & $74 \%$ & $31^{\circ}$ \\
\hline $120^{\circ}:$ & $\mathrm{Al}-0.2 \mathrm{Sc}$ & 0.73 & 2.2 & 3.0 & 0.89 & 1.39 & $64 \%$ & $27^{\circ}$ \\
\hline $90^{\circ}:$ & Al- $0.13 \mathrm{Mg}$ & 0.60 & 1.29 & 2.15 & 1.03 & 0.54 & $59 \%$ & $27^{\circ}$ \\
\hline $90^{\circ}:$ & $\mathrm{Al}-0.2 \mathrm{Sc}$ & 0.67 & 1.21 & 1.81 & 1.09 & 0.63 & $54 \%$ & $24^{\circ}$ \\
\hline \multicolumn{9}{|c|}{ Route $\mathbf{B}_{\mathrm{C}}$} \\
\hline Die: & Material & & & & & & & \\
\hline $120^{\circ}:$ & Al- $0.13 \mathrm{Mg}$ & 0.89 & 0.93 & 1.1 & 0.91 & 0.89 & $71 \%$ & $29^{\circ}$ \\
\hline $120^{\circ}:$ & Al- $0.2 \mathrm{Sc}$ & 2.4 & 5.4 & 2.3 & 1.3 & 1.84 & $46 \%$ & $19^{\circ}$ \\
\hline 90: & Al- $0.13 \mathrm{Mg}$ & 1.06 & 1.18 & 1.11 & 1.19 & 0.73 & $63 \%$ & $25^{\circ}$ \\
\hline 90: & $\mathrm{Al}-0.2 \mathrm{Sc}$ & 0.74 & 1.01 & 1.36 & 0.89 & 0.69 & $49 \%$ & $22^{\circ}$ \\
\hline
\end{tabular}

Table 1. Statistical data for the model alloys determined from the EBSD maps after deformation to a total effective strain of 10 by Route $A$ and $\mathrm{B}_{\mathrm{C}}$, using the $120^{\circ}$ and $90^{\circ}$ dies, for measurements from $\sim 5000$ grains. Showing; the grain sizes obtained, using the mean linear intercept $\lambda_{\mathrm{x}}$ parallel and $\lambda_{\mathrm{y}}$ perpendicular to the main direction of alignment, grain aspect ratio, equivalent circular diameter (ECD) grain size after grain reconstruction from the EBSD data, the standard deviation of the ECD grain size distributions normalised with respect to the mean diameter $\left(\sigma_{\mathrm{SD}} / \mathrm{d}_{\mathrm{m}}\right)$, the percentage of HAGB area, and the mean boundary misorientations.

On comparing the differences between the two materials, it is apparent that these are quite small in the case of the $90^{\circ}$ die, but previous work showing the evolution of severe deformation microstructures in a the same alloys using Route A convinces us that there is a consistent trend, in that the Al-0.2Sc dispersoid alloy refines more slowly during severe deformation processing than a single-phase alloy, irrespective of the die angle. With the statistical data, this is more convincing in the case of the $120^{\circ}$ die, but is readily apparent from the much larger retained grain fragments observable in the EBSD maps of the Al-0.2Sc alloy (Figs. 1b \& 1d) compared to the single-phase Al-0.13Mg alloy (Figs 1a \& 1b).

Severe deformation by Route $\mathbf{B}_{\mathbf{c}}$. EBSD maps of the two model alloys after deformation through the 90 and $120^{\circ}$ dies, to an effective strain of $\sim 10$ using Route $B_{C}$, are shown in Fig. 2. Due to the billet rotation, with Route $\mathrm{B}_{\mathrm{C}}$, at a continuum level there is no net macroscopic shape change of a material element, and much more isotropic grain structures are formed during severe deformation [2]. However, although the deformation structures are much less fibrous, they still tend to show preferential alignment with the shear direction from the last extrusion cycle. More importantly, it is immediately apparent that the differences noted between the two alloys deformed by Route A are now much more obvious with both die angles. In the case of the single-phase alloy (Figs. 2a \& 2c), the microstructure is comprised of a mixture of a matrix of aligned bands of low aspect ratio ultrafine grains and islands of coarser 'blocky' grain fragments, containing mainly subgrains (arrow Fig 2a). Overall, this leads to a slightly larger average ECD grain size than for Route A and a grain aspect ratio close to one (Table 1). There is also a wider spread in the normalised grain size distribution, reflecting the mixture of bands of very fine and coarse unrefined regions. Local line scans given in Fig.3a show that The LAGBs within the coarser grain fragments have significant misorientations of $\sim 5^{\circ}$, and are therefore well defined subgrains, which could easily be mistaken as grains in the TEM. 

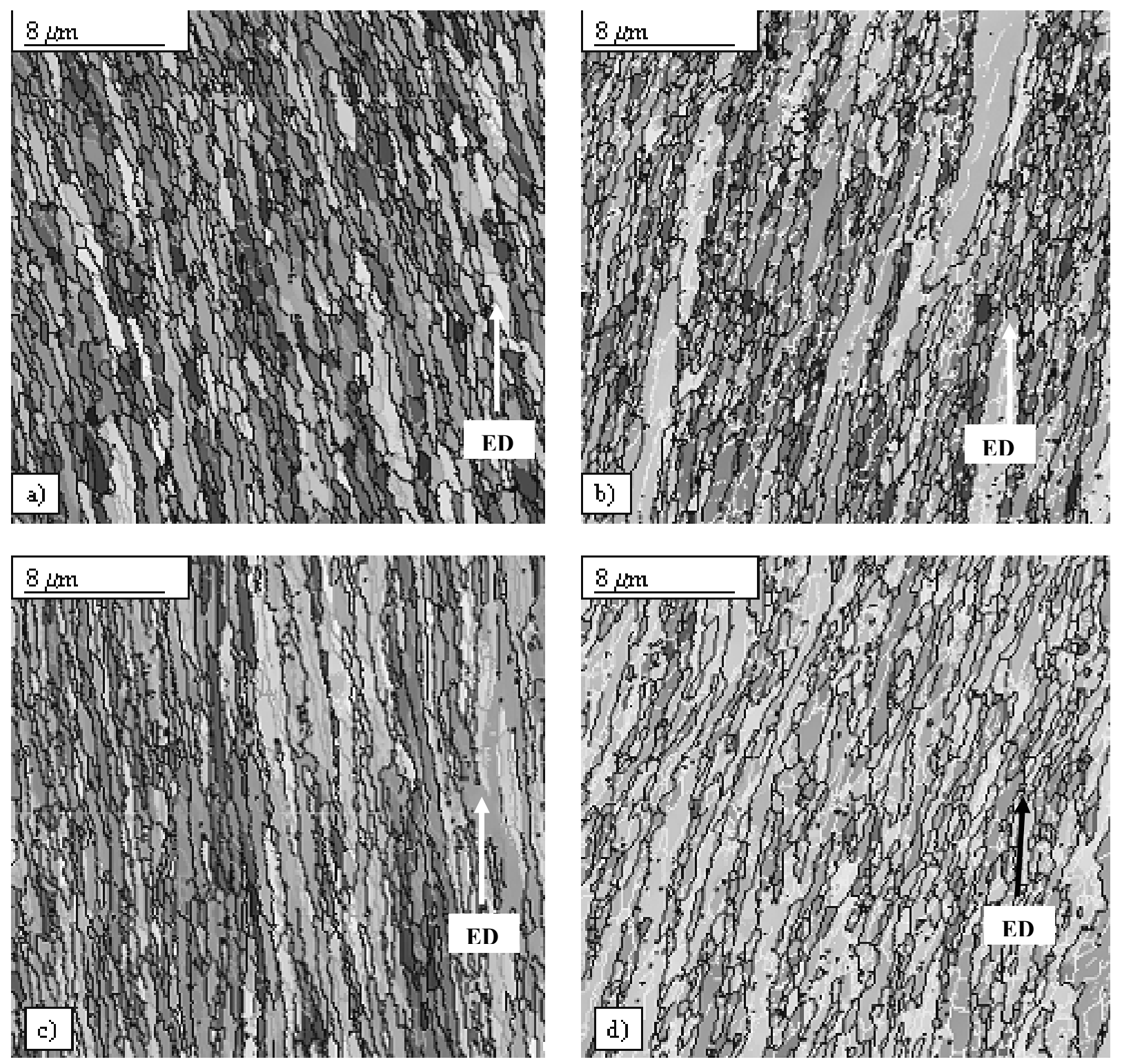

Figure 1. Typical areas from EBSD maps of the materials processed by Route $A$ at an $\varepsilon_{\mathrm{Vm}} \sim 10$, using a 120 and $90^{\circ}$ die; a) $\mathrm{Al} 0.13 \% \mathrm{Mg}$ with $120^{\circ} \mathrm{die}$, b) $\mathrm{Al} 0.2 \% \mathrm{Sc}$ with $120^{\circ} \mathrm{die}$, c) $\mathrm{Al} 0.13 \% \mathrm{Mg}$ with $90^{\circ}$ die , d) $\mathrm{Al} 0.2 \% \mathrm{Sc}$ with $90^{\circ}$ die.

Although for Route $\mathrm{B}_{\mathrm{C}}$ the fraction of HAGB area is consistently very slightly lower for both die angles than for Route $\mathrm{A}$, the difference is very small and probably insignificant. With Route $\mathrm{B}_{\mathrm{C}}$ there is also a much smaller difference between the two die angles, than was observed for Route A, with the $120^{\circ}$ die appearing to produce marginally more refinement.

Much more significant are the results for the dispersoid containing Al-0.2\%Sc alloy deformed by Route $\mathrm{B}_{\mathrm{C}}$ which, irrespective of the die angle, is predominantly comprised of subgrains and cannot be described as containing a submicron grain structure. The fraction of HAGB area is only 46 and $49 \%$, and the average boundary misorientation for this material was only 19 and $22^{\circ}$ for the 120 and $90^{\circ}$ die respectively. From inspection of Figs. $2 \mathrm{~b}$ and 2.d, it can be seen that in both cases the deformation structures contained only isolated bands of submicron grains, on the boundaries of coarse scale deformation bands. Line scans (Fig.3b) revealed that the LAGB misorientations of the subgrains within such bands were predominantly around $\sim 3-6^{\circ}$. The average 'grain sizes' determined in table 1 for this alloy are therefore somewhat misleading, as they are dominated by the larger numbers of small grains present, which are particularly fine in the case of the $90^{\circ}$ die. 
Overall it is apparent that with Route $\mathrm{B}_{\mathrm{C}}$ the rate of formation of new HAGB area has clearly been much more significantly affected by the presence of a high density of fine dispersoid particles than for Route A.
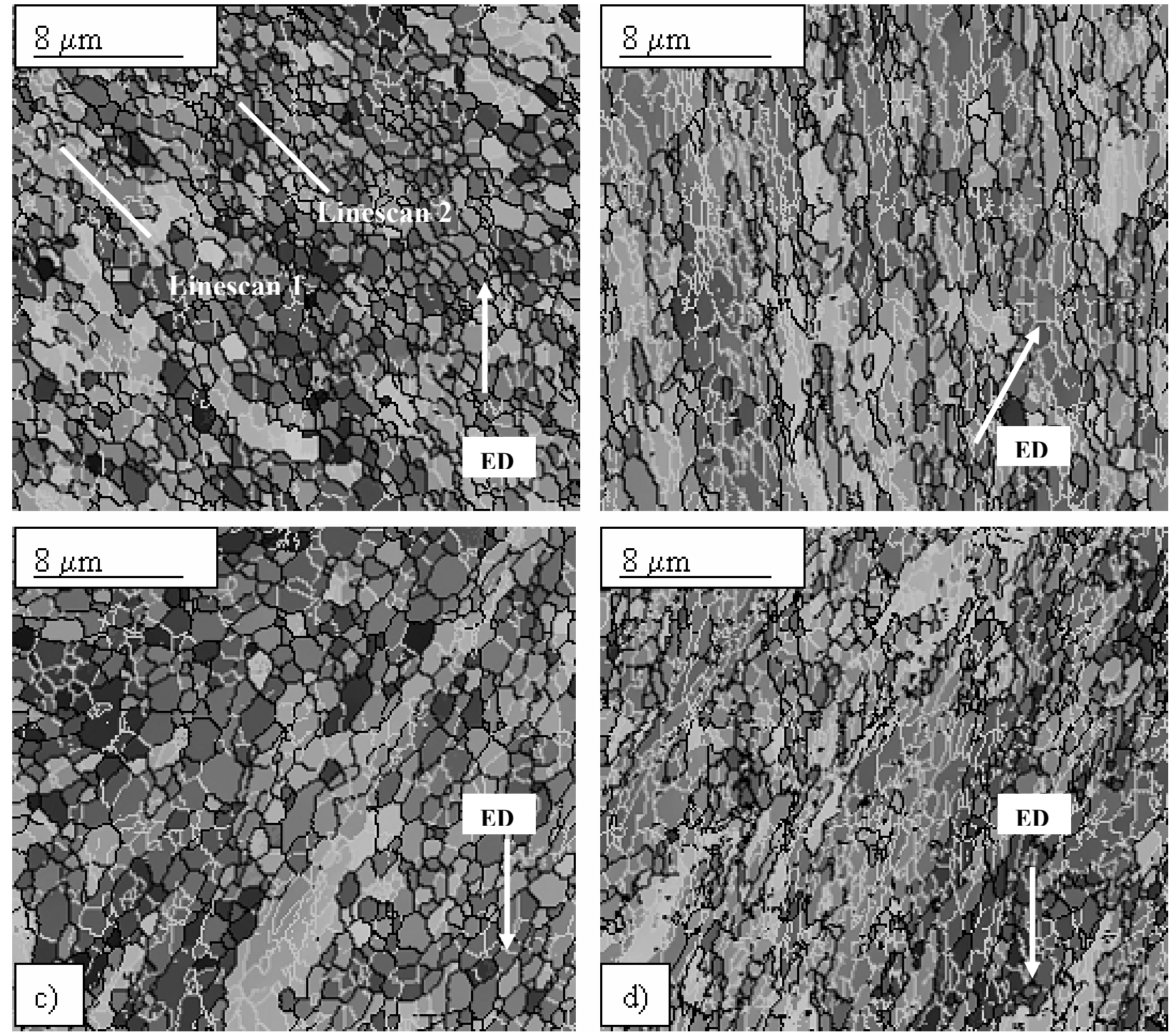

Figure 2. Typical areas from EBSD maps of the materials processed by route $\mathrm{B}_{\mathrm{C}}$ at an $\varepsilon_{\mathrm{vm}} \sim 10$, using a 120 and $90^{\circ}$ die; a) Al $0.13 \% \mathrm{Mg}$ with $120^{\circ}$ die, b) Al $0.2 \% \mathrm{Sc}$ with $120^{\circ}$ die, c) $\mathrm{Al} 0.13 \% \mathrm{Mg}$ with $90^{\circ}$ die , d) Al $0.2 \% \mathrm{Sc}$ with $90^{\circ}$ die.

Comparison of the Effect of Dispersoids on Grain Refinement With Route $A$ and $B_{C}$. In idealised ECAE deformation, where the deformation zone is restricted to a thin layer, the principle shear plane is the plane of intersection of the two die channels [9]. For Route A, without rotation of the billet, the shear plane rotates by $\pi-2 \phi$ each cycle [9]. However, a grid element in the sample coordinates is distorted by an apparent shear parallel to the billet axis, which accumulates each cycle. This leads to pre-existing grain boundaries, and permanent new boundaries, becoming rotated towards the extrusion direction, or billet axis. At the same time there is a geometric requirement for the transverse boundary spacing to be reduced with strain leading to the development of a fibrous grain structure. The geometric reduction in boundary spacing is given approximately by:

$$
\mathrm{d} / \mathrm{d}_{0}=1 /\left(\sqrt{1+\gamma^{2}}\right)
$$


where $\gamma$ is the accumulated shear strain and $\mathrm{d}_{0}$ is the initial grain size [11]. If it is assumed that the large original grains split into coarse $\sim 30 \mu \mathrm{m}$ deformation bands after the first cycle (see below), this geometric effect alone would mean that the transverse high angle boundary space using route $\mathrm{A}$ would approach $\sim 4 \mu \mathrm{m}$ by a strain of $\varepsilon_{\mathrm{vm}}=10$.

In the single-phase Al-0.13Mg alloy, the deformation structure evolution during ECAE processing by Route A has already been reported [e.g. 2,3]. At low strains (1 pass) dislocations dynamically recover into a banded cellular structure divided by low misorientation subgrain boundaries. The dense dislocation walls that delineate the cell bands are frequently found to be parallel to the die's plane of intersection, or the principal shear plane, and are thus probably transient features which are destroyed and reform each cycle [3,8]. Grains of unstable orientation subdivide on a coarse scale by the formation of deformation bands. Further deformation leads to the formation of micro-shear bands (at $\varepsilon_{\mathrm{vm}} \sim 2$ ), due to instability in plastic flow, which can be intense enough to generate new HAGB segments of relatively low misorientation $\left(15-30^{\circ}[3,8]\right)$. The original grain boundaries, and new HAGBs formed at deformation band boundaries and microshear bands, are permanent and rotate towards the billet axis, while their spacing becomes compressed with strain, until they form a fine lamellar structure. As the transverse spacing approaches the subgrain size, these thin high aspect ratio grains progressively break up to form the submicron-grained structure seen at ultra-high strains. This occurs heterogeneously, initiating in bands of high HAGB density.

In the case of deformation by Route $\mathrm{B}_{\mathrm{C}}$, which involves shear on four alternate planes, the net strain is redundant and an element returns to its original shape every four cycles. This means that there is no geometric requirement for any pre-existing HAGBs to extend in area, or compress in spacing, with accumulated strain. The mechanisms by which grain refinement occurs under these conditions are still poorly understood, but are believed to be predominantly due to new HAGBs being generated from deformation bands caused by orientation instability and microshear bands. Shear bands are promoted in ECAE due to instability in flow being encouraged by the reorientation of the shear direction, relative to the original principal direction of alignment of dense dislocation boundaries formed in the previous cycle [2]. This leads to the heterogeneous deformation structures seen in Figs. 2a, and 2c comprised of bands of fine grains in regions of high local strain formed by shear bands and retained islands of subgrains.

With Route A the level of grain refinement appeared to be reduced in the dispersoid-containing alloy, compared to the single-phase alloy, particularly with the $120^{\circ}$ die. This reduction in the level of grain refinement, owing to the presence of a high density of dispersoids, was far more noticeable using Route $\mathrm{B}_{\mathrm{C}}$. With Route $\mathrm{A}$, it has been found that a high density of $\mathrm{Al}_{3} \mathrm{Sc}$ dispersoids inhibits both the formation of cells and sharp DDWs, which define the cell band structures seen at moderate strains in single-phase alloys [8]. The more weakly misorientated and diffuse dislocation boundaries formed in the dispersoid-containing alloy, plus the homogenisation of slip, prevents the formation of microshear bands during subsequent cycles, which blocks this important mechanism of HAGB formation. The main source of new HAGB area generation in the dispersoid containing alloy at low to medium strains is therefore restricted to the formation of coarse deformation bands, and the extension of these, and the original grain boundaries due to the geometric shape change of an element with strain. This in turn delays the formation of a lamellar HAGB structure and the development of a uniform submicron grained material at ultra-high strains. In the case of processing with rotation of the billet by route $\mathrm{B}_{\mathrm{C}}$, there is no net geometric shape change of an element to increase the HAGB area and reduce the HAGB separation with strain. Thus, by reducing the tendency for the formation of shear bands, which is now the main mechanism of forming new 
HAGB area with this processing Route, the finely spaced dispersiods appear in this case to have a more dramatic effect on inhibiting grain refinement.

a) Linescan $1 \mathrm{Al}-0.13 \% \mathrm{Mg}$ LAGBs area
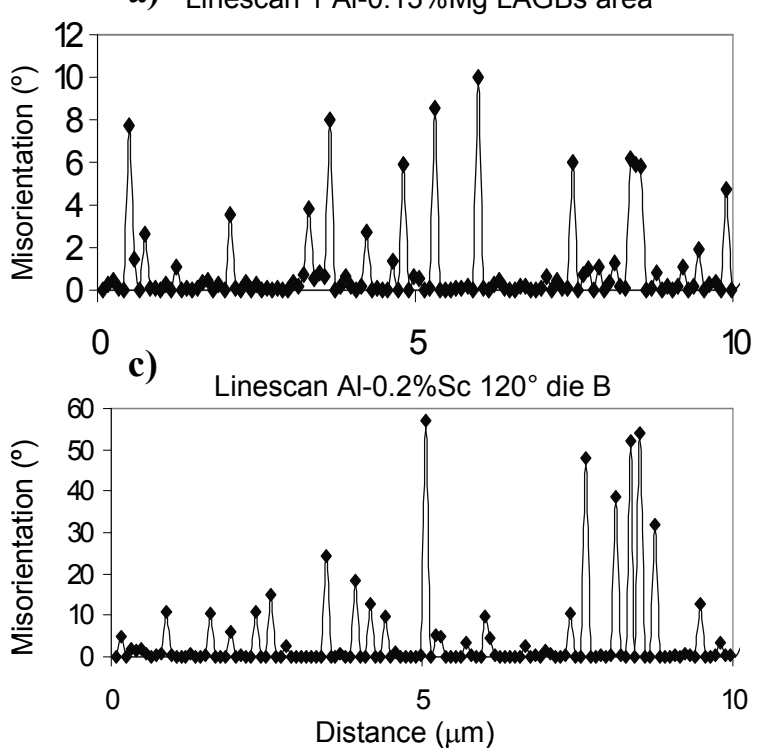

b) Linescan $2 \mathrm{Al}-0.13 \% \mathrm{Mg} \mathrm{HAGB}$ area

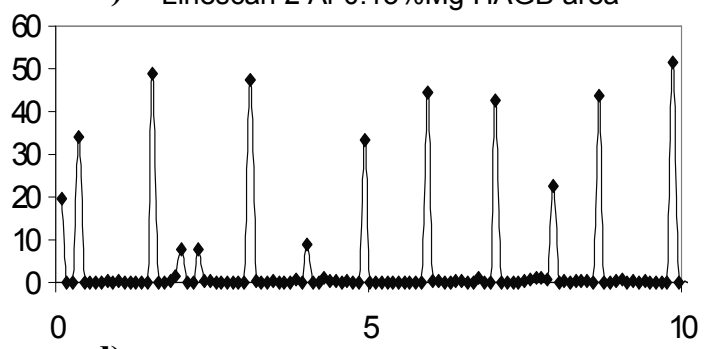

d) Linescan $\mathrm{Al} 0.2 \% \mathrm{Sc} 90^{\circ}$ die $\mathrm{Bc}$

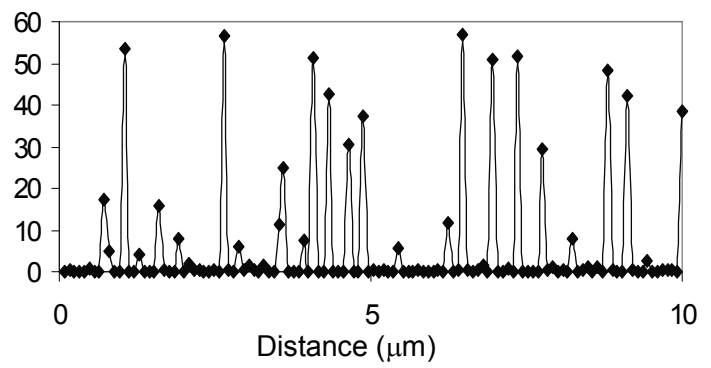

Figure 3. Relative boundary misorientation Linescans from (a) a LAGB and a HAGB area in the region the EBSD map of the $\mathrm{A} 10.13 \% \mathrm{Mg}$ alloy deformed by route $\mathrm{B}_{\mathrm{C}}$ (shown in Fig. 2.a) with the $120^{\circ}$ die (Note the different misorientation scales) and (b) from the Al- $0.2 \% \mathrm{Sc}$ alloys with the 120 and $90^{\circ}$ die, processed by Route $\mathrm{B}_{\mathrm{C}}$.

This important effect of dispersoids severely inhibiting the formation of a true submicron grain structure in severely deformed alloys occurred irrespective of the die angle. Altering the die angle from 120 to $90^{\circ}$, changes the ideal shear strain per extrusion cycle from 1.15 to 2 , but reduces the total number of cycles to obtain the same strain (from 15 to 9 in this case). It also alters the angle of intersection of the shear planes. The most notable result of the different die angle was to reduce the level of refinement using Route $A$ in the case of a $90^{\circ}$ die, but this effect was less apparent with Route $\mathrm{B}_{\mathrm{C}}$. This behaviour is currently difficult to explain and requires further investigation. In this context it is interesting that Dupuy and Rauch [7] have shown in ECAE processing that theoretically the magnitude of the strain path change for Route A, is more sensitive to die angle than with Route $\mathrm{B}_{\mathrm{C}}$.

\section{Conclusions}

The influence of fine, non-shearable, dispersoids on the level of grain refinement during severe deformation of aluminium by ECAE, through Routes $\mathrm{A}$ and $\mathrm{B}_{\mathrm{C}}$ has been investigated, using a $120^{\circ}$ and $90^{\circ}$ die. The microstructure development with strain in an Al-0.2\%Sc dispersoid containing alloy was compared to an Al- $0.13 \% \mathrm{Mg}$ single-phase alloy, using high resolution EBSD analysis. With Route A the presence of fine dispersoids was found to significantly retard grain refinement, but this effect was much greater after deformation by Route $\mathrm{B}_{\mathrm{C}}$. It is thought that this behaviour is related to high densities of fine dispersoids inhibiting the formation of micro-shear bands, which is the main source of new HAGB area with Route $\mathrm{B}_{\mathrm{C}}$. Similar results were obtained with the two die angles, but with Route A refinement tended to be less effective with the $90^{\circ}$ die. 


\section{Acknowledgements}

This work was supported by the Manchester EPSRC Portfolio Partnership in Light Alloy for Environmentally Sustainable Transport (EP/D029201/1). M. Berta is also grateful to the Armourers and Braziers Society for meeting his travel expenses to attend the conference.

\section{References}

[1] R.Z. Valiev, R.K. Islamgaliev and I.V. Alexandrov: Prog. in Mat. Sci. Vol. 45 (2000), p. 103.

[2] P.B. Prangnell, J.R. Bowen, and A. Gholinia: In Proceedings of $22^{\text {nd }}$ Risø Int. Symposium, Science of Metastable and Nanocrystalline alloys, edited by A.R. Dinesen et al., Risø National Laboratory, Roskilde Denmark, (2001), p. 105.

[3] P.B. Prangnell, J.R. Bowen, and P.J. Apps: Mat. Sci. Eng. A Vol. 375-377 (2004), p. 178.

[4] F. Dalla Torre, R. Lapovok, J. Sandlin, P.F. Thomson, C.H.J. Davies and E.V. Pereloma: Acta Mater. Vol. 52 (2004), p. 4819.

[5] A. Gholina, P.B. Prangnell, and M.V. Markushev: Acta Mater. Vol. 48 (2000), p.1115.

[6] Y. Iwahashi, Z. Horita, M. Nemoto, and T.G. Langdon: Acta Mater. Vol. 45 (1997), p. 4733.

[7] L. Dupuy, and E.F. Rauch: Mater. Sci. Eng. Vol. A337 (2002), p. 241.

[8] P.J. Apps, M. Berta, and P.B. Prangnell: Acta Mater. Vol. 53 (2005), p. 499.

[9] V.M. Segal: Mater. Sci. Eng. A Vol. 271(1999), p. 322.

[10] J.R. Bowen: The formation of ultra-fine grained model aluminium and steel alloys. $\mathrm{PhD}$ Thesis, UMIST, UK, (2000).

[11] F.J. Humphreys, P.B. Prangnell, J.R. Bowen, A. and C. Harris: Phil. Trans. Royal Society London A, Vol. 357 (1999), p. 1663. 
High Pressure Technology of Nanomaterials

doi:10.4028/www.scientific.net/SSP.114

The Effect of Dispersoids and Processing Variables on Grain Refinement of Aluminium Alloys Deformed by ECAE

doi:10.4028/www.scientific.net/SSP.114.151 